УДК 338.012

DOI 10.18101/2304-4446-2020-3-31-40

\title{
ФАРМАЦЕВТИЧЕСКАЯ ОТРАСЛЬ В РОССИИ: АНАЛИЗ И ЭКОНОМИЧЕСКИЕ АСПЕКТЫ РАЗВИТИЯ
}

\author{
(C) Раднаева Светлана Эрнстовна \\ кандидат экономических наук \\ E-mail: radnasv@gmail.com
}

(C) Мацкевич Ирина Владимировна

кандидат социологических наук, доцент

E-mail: mazkevich@yandex.ru

\section{(c) Ухакшинова Елена Маркеловна}

ассистент

E-mail: ukh.elema@mail.ru

Бурятский государственный университет имени Доржи Банзарова

Россия, 670000, г. Улан-Удэ, ул. Смолина, 24а

За последние 10 лет фармацевтическая отрасль России является динамично растущим несырьевым сектором экономики и ежегодно демонстрирует активный устойчивый рост, превосходящий рост всей остальной экономики в целом. В статье приводится анализ развития отрасли по основным экономическим показателям за последние 7-10 лет в сравнении с важнейшими показателями народного хозяйства; основные валовые показатели и индексы организаций по видам экономической деятельности - производство фармацевтической продукции, фармацевтических субстанций и производства лекарственных препаратов и материалов, применяемых в медицинских целях. Выявлены основные тренды инвестиций в основной капитал в фармацевтической промышленности, определена структура объема отгруженных товаров собственного производства, выполненных работ и услуг собственными силами по формам собственности, приведены индексы предпринимательской уверенности организаций обрабатывающих производств и фармацевтической промышленности. Представлены основные результаты государственной политики по развитию фармацевтической отрасли, обозначенной в Федеральной целевой программе «ФАРМА-2020», новые приоритеты проекта новой стратегии «ФАРМА-2030».

Ключевые слова: фармацевтическая отрасль; фармацевтическая промышленность; стратегия «ФАРМА-2020»; стратегия «ФАРМА-2030».

\section{Для цитирования}

Раднаева С. Э., Мацкевич И. В., Ухакшинова Е. М. Фармацевтическая отрасль в России: анализ и экономические аспекты развития // Вестник Бурятского государственного университета. Экономика и менеджмент. 2020. № 3. С. 31-40.

Фармацевтическая отрасль - это отрасль экономики, занимающаяся исследованиями, разработкой, массовым производством и дистрибуцией лекарственных препаратов широкого спектра - синтетических, биологических, натуральных, преимущественно предназначенных для профилактики, облегчения и лечения болезней, а также компонентов для косметических средств и пищевых продуктов. 
Фармацевтическая отрасль является важнейшей составляющей стратегии национальной и политической безопасности государства, а также одним из высокодоходных и быстроразвивающихся сегментов мировой и отечественной экономики, слабо зависящих от экономических подъемов и спадов. Лекарственное обеспечение населения как в России, так и за рубежом относится к важным показателям социального развития общества и индикатором благосостояния.

В свою очередь, фармацевтическая промышленность - это базис фармацевтической отрасли, оказывающей влияние на ситуацию в здравоохранении, страховании, бюджетном процессе на всех уровнях, формировании занятости населения и в других сферах, а также взаимодействующей с другими отраслями народного хозяйства - химическая и биотехнологическая промышленность, машиностроение, сельское хозяйство, военно-промышленный комплекс, научные исследования и разработки и др.

Фармацевтическая промышленность включает научно-производственные предприятия, специализирующиеся на выпуске синтетических лекарственных средств, препаратов из растительного сырья, витаминов, ферментов, антибиотиков, эндокринных препаратов, кровезаменителей, галеновых препаратов ${ }^{1}$, кетгу$\mathrm{Ta}^{2}$ и бактерийных медицинских препаратов.

Структура отечественной фармацевтической промышленности не однородна и представлена несколькими видами предприятий:

- постсоветские фармацевтические предприятия, у которых есть лицензии на производство лекарственных средств, но которые имеют большие финансовые проблемы, затрудняющие переход этих предприятий на стандарты GMP;

- «нишевые» предприятия с небольшими производственными мощностями, работающие на базе бывших научно-исследовательских институтов;

- контрактные производства, выпускающие продукцию на основе кооперации с иностранными партнерами;

- предприятия с современным производством, которое соответствует международным стандартам.

Технико-экономическими особенностями фармацевтической промышленности, оказывающими влияние на ее производственно-хозяйственную деятельность, являются:

- высокая производительность труда и малотоннажность производства;

- систематическое обновление номенклатуры производимых лекарственных препаратов,

- длительный производственный цикл и сложность технологических процессов;

- повышенные требования к качеству выпускаемой продукции.

${ }^{1}$ Гале́новые препара́ты - группа лекарственных средств, получаемых из растительного сырья путем вытяжки (экстракции). Чаще всего это настойки (спиртовые или водноспиртовые вытяжки) или экстракты (сгущенные вытяжки).

${ }^{2}$ Кетгу́т (англ. catgut, сокращение от «cattlegut» — «кишечник крупного рогатого скота») - саморассасывающийся хирургический шовный материал, который изготовляют из очищенной соединительной ткани, полученной либо из серозного слоя кишечника крупного рогатого скота, либо из подслизистой оболочки кишечника овец. 
С. Э. Раднаева, И. В. Мацкевич, Е. М. Ухакшинова. Фармацевтическая отрасль в России: анализ и экономические аспекты развития

Фармацевтическая промышленность представляет собой один из наукоемких и высокотехнологичных секторов экономики и занимает второе место в мире среди таких отраслей, как аэрокосмическая, производство компьютерной техники и радиоэлектроники, современных средств связи, медицинских и оптических инструментов.

В России, по данным Министерства промышленности и торговли РФ, наиболее восприимчивым к технологическим инновациям сектором экономики в настоящее время является промышленность, а фармацевтика входит в перечень самых инновационно активных отраслей наряду с химической промышленностью, отдельными сегментами машиностроения и производством электрооборудования [1].

Так, производство фармацевтической продукции в России относится к высокотехнологичным видам экономической деятельности (код ОКВЭД 24.4 «Производство фармацевтической продукции»). Следует отметить, что после 2014 г. принят ОКВЭД в новой редакции и сменилось наименование, далее упоминаемое в изданиях Росстата как ОКВЭД 2 код 21 «Производство лекарственных средств и материалов, применяемых в медицинских целях» ${ }^{1}$.

Таблица 1

Индексы валового внутреннего продукта и индексы производства промышленности, обрабатывающей и фармацевтической промышленностей за 2014-2020 гг., \% к предыдущему году (периоду) ${ }^{2}$

\begin{tabular}{|c|c|c|c|c|c|c|c|c|c|c|c|}
\hline Наименование & 옴 & ন্: & ָั & $\stackrel{m}{\stackrel{n}{N}}$ & 离 & นุ: & $\stackrel{0}{\circ}$ & ન્- & $\stackrel{\infty}{\stackrel{\infty}{N}}$ & 공 & $\begin{array}{c}1 \text { Kв. } \\
2020 \\
\text { K } 1 \\
\text { КВ. } \\
2019\end{array}$ \\
\hline ВBП & 104,5 & 104,3 & 103,5 & 101,3 & 100,7 & 97,2 & 99,8 & 101,5 & 102,5 & 101,3 & - \\
\hline $\begin{array}{l}\text { Промышленное } \\
\text { производство }\end{array}$ & 107,3 & 106 & 103,4 & 100,4 & 101,7 & 96,6 & 101,1 & 102,1 & 102,9 & 102,3 & 101,5 \\
\hline $\begin{array}{l}\text { Обрабатываю- } \\
\text { щие производ- } \\
\text { ства }\end{array}$ & 111,8 & 106,5 & 104,1 & 100,5 & 101,2 & 94,6 & 101,1 & 100,2 & 103,6 & 102,6 & 103,8 \\
\hline $\begin{array}{l}\text { Фармацевтиче- } \\
\text { ская промыш- } \\
\text { ленность }\end{array}$ & 134,1 & 117,4 & 118,2 & 107,8 & 94,6 & 108,5 & 127,5 & 112,7 & 108,2 & 121,6 & 111,8 \\
\hline
\end{tabular}

${ }^{1}$ Общероссийский классификатор видов экономической деятельности ОК 029-2014 (КДЕС Ред. 2) - утвержден Приказом Росстандарта от 31.01.2014 N 14-ст с введением в действие с 1 февраля 2014 г. ОКВЭД 2 представлен в редакции 2020 года со всеми изменениями и дополнениями.

2 Социально-экономическое положение России: доклад Федеральной государственной службы России (Росстат) январь - февраль 2020, декабрь 2018, январь 2015. URL: https://gks.ru/compendium/document/50801 (дата обращения: 10.08.20). 
За последние 10 лет фармацевтическая отрасль России является динамично растущим несырьевым сектором экономики и ежегодно демонстрирует активный устойчивый рост, превосходящий рост всей остальной экономики в целом. Индексы роста фармацевтической промышленности ежегодно на протяжении всего периода (за исключением 2014 г.) заметно превышают индекс валового внутреннего продукта, промышленного производства и подотрасли промышленности - обрабатывающих производств, куда относится фармацевтическая промышленность.

Следует отметить, что среднее превышение индекса производства фармацевтической промышленности по сравнению с индексом промышленного производства составляло порядка $14 \%$ за рассматриваемый период. В первом квартале 2020 г. также наблюдается опережающий рост фармпромышленности.

Объемы производства фармацевтической продукции имеют устойчивую тенденцию роста, несмотря на то, что представлены в разных периодах по измененным кодам ОКВЭД, принятым Росстатом. Следует отметить, что учет показателей по фармацевтической промышленности осуществляется только за последние 5 лет, более детально с 2016 г. (табл. 2).

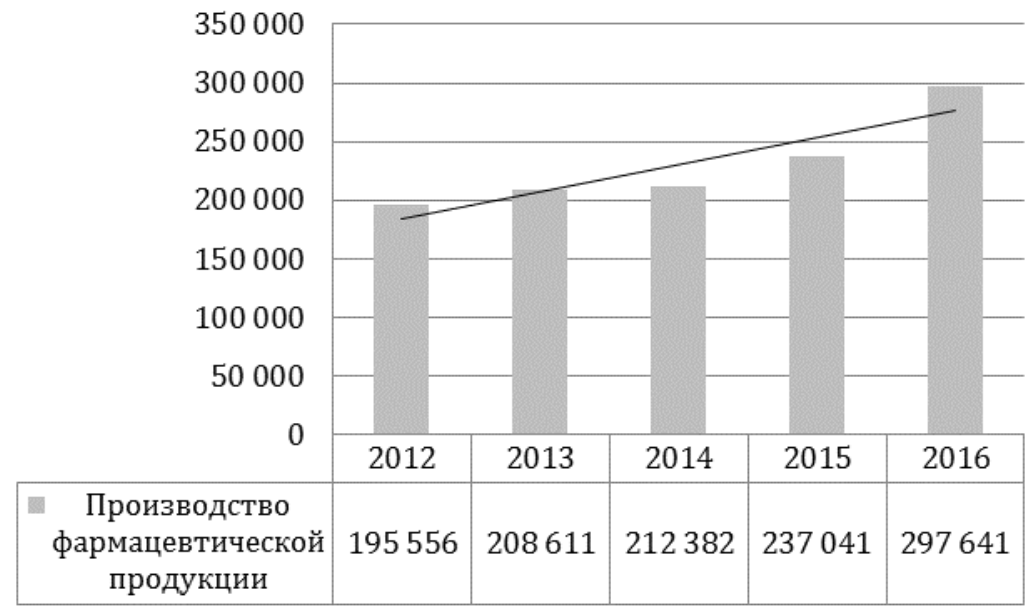

Рис. 1. Производство фармацевтической продукции (код ОКВЭД 24.4) в России за 2012-2016 гг., млн руб.

Так, с 2012 г. прирост производства фармацевтический продукции за 3 года был умеренным, в среднем составлял $2-7 \%$ в год. Особенно заметен рост этого показателя в 2015 и 2016 гг. - на 11,6 и 25,6\% соответственно. Что касается динамики развития отрасли в последующем, то, несмотря на ограниченность наблюдения за показателями, характеризующими состояние фармацевтической промышленности, очевидными становятся наметившиеся положительные тренды в отрасли.

С 2016 по 2018 г. для фармацевтической промышленности характерна следующая динамика развития отрасли:

- устойчивый рост оборота и объема отгруженных товаров с некоторым замедлением в 2018 г. объема производства свыше 30\% на фоне сокращения числа предприятий на 20 \% (546 единиц) и снижения численности работников в отрасли; 
С. Э. Раднаева, И. В. Мацкевич, Е. М. Ухакшинова. Фармацевтическая отрасль в России: анализ и экономические аспекты развития

- высокая рентабельность продукции свыше $20 \%$ и высокая рентабельность активов 8,1\% в 2018 г., что означает 8,1 р. прибыли получено на 1 р. активов фармпредприятий;

- улучшение финансового результата в целом по отрасли - 24,6 млн р. на одно предприятие;

- наличие убыточных организаций - почти каждое третье предприятие, убыток которых составляет порядка $15,1 \%$ от совокупного оборота, или 14,2 млн р. на одно убыточное предприятие.

Таблица 2

Основные показатели организаций по виду экономической деятельности производство лекарственных средств и материалов, применяемых в медицинских целях (код ОКВЭД 2 21) за 2014-2018 гг. ${ }^{1}$

\begin{tabular}{|c|c|c|c|}
\hline Наименование & 2016 & 2017 & 2018 \\
\hline Оборот организаций로 млрд р. & 425 & 485 & 549 \\
\hline $\begin{array}{l}\text { Объем отгруженных товаров собственного производства, вы- } \\
\text { полненных работ и услуг собственными силами }{ }^{3}, \text { млрд р. }\end{array}$ & 417 & 500 & 558 \\
\hline Число предприятий и организаций (на конец года) & 2676 & 2425 & 2130 \\
\hline Среднегодовая численность работников организаций, тыс. чел. & & 70,5 & 68,6 \\
\hline \multicolumn{4}{|l|}{ в том числе: } \\
\hline производство фармацевтических субстанций & - & 13 & 6,4 \\
\hline $\begin{array}{l}\text { производство лекарственных препаратов и материалов, при- } \\
\text { меняемых в медицинских целях }\end{array}$ & - & 57,4 & 62,2 \\
\hline $\begin{array}{l}\text { Сальдированный финансовый результат (прибыль минус убы- } \\
\text { ток) деятельности организаций в фактически действовавших } \\
\text { ценах, млн р. }\end{array}$ & & $\begin{array}{c}54 \\
387\end{array}$ & $\begin{array}{c}56 \\
277\end{array}$ \\
\hline Рентабельность продукции (товаров, работ, услуг), \% & - & 25,0 & 21,6 \\
\hline Рентабельность активов организаций, \% & & 9,0 & 8,1 \\
\hline $\begin{array}{l}\text { Удельный вес убыточных организаций, \% от общего числа ор- } \\
\text { ганизаций }\end{array}$ & - & - & 28,1 \\
\hline Сумма убытка, млн р. & & & 8489 \\
\hline
\end{tabular}

${ }^{1}$ Федеральная государственная служба России (Росстат). Российский статистический ежегодник. 2017, 2018, 2019. URL: https://www.gks.ru/folder/210/document/12994 (дата обращения: 10.08.20).

${ }^{2}$ В оборот организаций включается стоимость отгруженных товаров собственного производства, работ и услуг, выполненных собственными силами, а также выручка от продажи приобретенных ранее на стороне товаров (без налога на добавленную стоимость, акцизов и аналогичных обязательных платежей).

${ }^{3}$ Объем отгруженных товаров собственного производства представляет собой стоимость тех товаров, которые произведены данным юридическим лицом и фактически отгружены или отпущены в порядке продажи, а также прямого обмена на сторону (другим юридическим и физическим лицам) в отчетном периоде, независимо от того, поступили деньги на счет продавца или нет. 
Фармацевтическая промышленность по направлениям деятельности согласно коду $21^{1}$ ОКВЭД 2 включает группировки:

- производство фармацевтических субстанций, лекарственных препаратов, применяемых в медицинских целях;

- производство химических препаратов и веществ на основе трав, применяемых в медицинских целях.

Сведения по темпам роста производств фармацевтической промышленности Росстатом приводятся начиная с 2016 г. и представлены в таблице 3.

Таблица 3

Индексы фармацевтической промышленности, производства фармацевтических субстанций и производства лекарственных препаратов и материалов, применяемых в медицинских целях за 2016-2018 гг. 2, \%

\begin{tabular}{|l|c|c|c|}
\hline \multicolumn{1}{|c|}{ Наименование } & 2016 & 2017 & 2018 \\
\hline Фармацевтическая промышленность & 127,5 & 112,7 & 108,2 \\
\hline в том числе: & & & \\
\hline производство фармацевтических субстанций & 160,5 & 121,4 & 121,8 \\
\hline $\begin{array}{l}\text { производство лекарственных препаратов и материа- } \\
\text { лов, применяемых в медицинских целях }\end{array}$ & 117,2 & 107,6 & $\mathbf{9 8 , 8}$ \\
\hline
\end{tabular}

За наблюдаемый период обращает на себя внимание значительно более высокими темпами роста производство фармацевтических субстанций по сравнению с производством лекарственных препаратов и материалов, применяемых в медицинских целях, что, очевидно, сопряжено с реализацией государственной политики по восстановлению отечественного производства субстанций. По состоянию на 2018 г. отечественные компании производят всего около 15\% необходимых активных фармацевтических субстанций.

Однако во времена плановой экономики Советский Союз не только обеспечивал потребности отечественной фармпромышленности, но и являлся крупнейшим мировым экспортером. До 1992 г. отечественные предприятия обеспечивали «первичным фармацевтическим сырьем» республики Советского Союза и почти всю Восточную Европу. Потребителями являлись предприятия стран Варшавского договора (ГДР, Венгрия, Чехословакия, Польша, Болгария) и Югославии, выпускающие готовые лекарственные средства.

Практически полностью было прекращено производство собственных субстанций, а с 1992 по 2008 г. объем их производства сократился в 18 раз [2]. Так, переход на рыночную экономику в 1990-х гг. сопровождался глубоким кризисом в фармацевтической промышленности, в том числе в производстве фармацевти-

\footnotetext{
${ }^{1}$ Расшифровка кода ОКВЭД 21, класс «Производство лекарственных средств и материалов, применяемых в медицинских целях»: код ОКВЭД 21.1 Производство фармацевтических субстанций; код ОКВЭД 21.2. Производство лекарственных препаратов и материалов, применяемых в медицинских целях.

${ }^{2}$ Социально-экономическое положение России: доклад Федеральной государственной службы России (Росстат). 2017, 2018, 2019. URL: https://gks.ru/compendium/document/ 50801 (дата обращения: 10.08.20).
} 
ческих субстанций. Первым и ощутимым стало катастрофическое падение объемов реализации субстанций, выпускаемых отечественными заводами 1 :

- производство субстанций в натуральном выражении снижалось вплоть до 2002 г., после - медленный рост, который к 2005 г. достиг 2860 тонн, то есть всего $16 \%$ от уровня 1992 г.

- производство субстанций для антибиотиков упало более чем в 40 раз в 2005 г. от показателей 1992 г., а к 2007 г. прекратилось вообще;

- вследствие резкого снижения объемов производства субстанций произошло уменьшение мощностей по их выпуску, в среднем на $60 \%$ в 2005 г. по сравнению с 1992 г.

- произошел демонтаж или утрачено значение производства порядка 132 наименований субстанций.

В 1992 г. в России производилось 272 наименования субстанций объемом в 17,5 тыс. условных тонн, что не только обеспечивало потребности производства препаратов в разных сегментах от 70 до $100 \%$, но и позволяло экспортировать в дружественные страны. После распада СССР экономические связи разрушились, многие российские заводы по выпуску субстанций закрылись.

По данным маркетингового агентства DSM Group, в 2018 г. в Россию завезли свыше 770 различных наименований АФС. На территории России уже разворачивается ряд инвестиционных проектов как иностранных, так и российских компаний. Соотношение иностранных и российских поставщиков активных фармацевтических субстанций (АФС) для производства препаратов на территории РФ составляет 90 к 10. Так, по данным Ассоциации международных фармацевтических производителей, за 10 лет иностранные компании вложили в российское фармпроизводство более 1 трлн $\mathrm{p}$.

В свою очередь, проект госпрограммы «Фарма-2030», представленный российским правительством около года назад, определяет одной из приоритетных задач расширение присутствия российских препаратов на экспортных рынках. По мнению директора российской фармкомпании «Герофарм» Петра Родионова, «собственное производство фармацевтических субстанций российскими компаниями - необходимое условие для создания прорывных технологий, выхода на внешние рынки и трансфера технологий. Сейчас важно наращивать и углублять компетенции. А это возможно только при развитии производства субстанции на территории России» ${ }^{2}$.

Инвестиции в основной капитал в фармацевтической промышленности имеют в целом тренд роста с 2014 по 2018 г., за исключением 2016 г. Рост инвестиционной активности фармпредприятий составил 15,3\%, или 5,4 млрд р., в 2018 г. по сравнению с началом наблюдаемого периода 2014 г.

Объем инвестиций в фарминдустрии, несмотря на рост, все же еще незначителен и составляет в 2018 г. всего $0,2 \%$ от общих инвестиций в основной капитал по видам экономической деятельности и $1,6 \%$ от инвестиций в подотрасли про-

1 Производство фармацевтических субстанций: пока ставим плюс. URL: https://ecobaltic.com/novosti/proizvodstvo-farmacevticheskih-substancij (дата обращения: 10.08.20).

2 Автономия по существу // Коммерсант. Приложение «Здравоохранение». 2019. № 133. 30 июля. URL: https://www.kommersant.ru/doc/4046145 (дата обращения: 10.08.20). 
мышленности - обрабатывающие производства. Инвестиции в основной капитал на 1 предприятие на фоне снижения числа предприятий растет более высокими темпами за последние два года наблюдаемого периода, на 37,0 и 30,5\% соответственно.
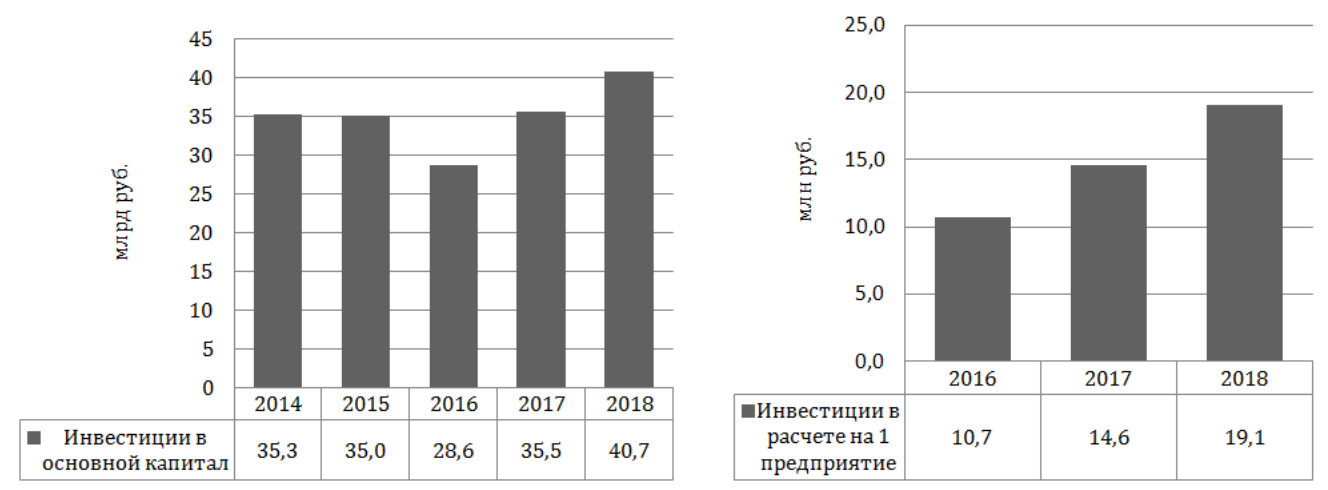

Рис. 2. Инвестиции в основной капитал в производстве лекарственных средств и материалов, применяемых в медицинских целях за 2014-2018 гг.

Объем отгруженных товаров собственного производства, выполненных работ и услуг собственными силами по формам собственности отражает распределение доли влияния. Иностранные фармкомпании на территории России и совместные с иностранными занимают довольно существенную долю - 36,5\%.

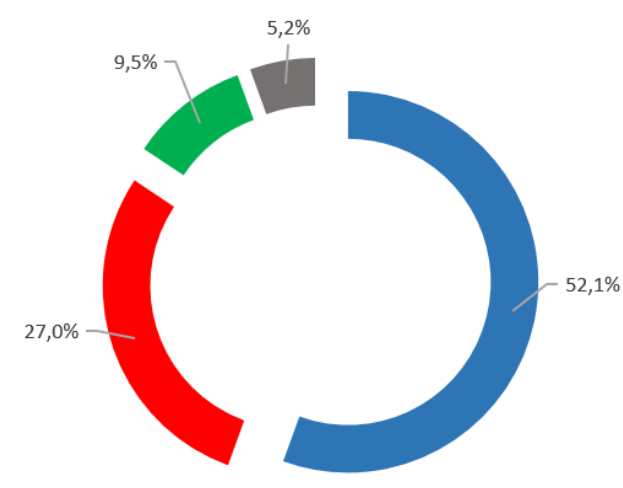

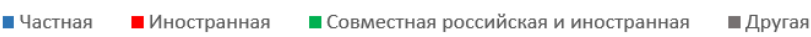

Рис. 3. Объем отгруженных товаров собственного производства, выполненных работ и услуг собственными силами по формам собственности в 2018 г.

в фактически действовавших ценах, \%

По данным обследования деловой активности в фармацевтической промышленности значение индекса предпринимательской уверенности относительно перспектив развития показывает рост 3-4 \% ежемесячно. В то время как обрабатывающие производства находятся в отрицательной зоне по результатам первого квартала 2020 г. 
Индекс предпринимательской уверенности организаций обрабатывающих производств и фармацевтической промышленности в январе - апреле 2020 г. (без малых предприятий $)^{1}, \%$

\begin{tabular}{|l|c|c|c|c|}
\hline \multirow{2}{*}{ Наименование } & \multicolumn{4}{|c|}{2020} \\
\cline { 2 - 5 } & январь & февраль & март & апрель \\
\hline $\begin{array}{l}\text { Обрабатывающие } \\
\text { производства }\end{array}$ & $-\mathbf{3}$ & $\mathbf{- 2}$ & $\mathbf{- 2}$ & $\mathbf{- 7}$ \\
\hline $\begin{array}{l}\text { Производство лекар- } \\
\text { ственных средств и } \\
\begin{array}{l}\text { материалов, приме- } \\
\text { няемых в медицин- } \\
\text { ских целях }\end{array}\end{array} \quad \mathbf{4}$ & $\mathbf{3}$ & $\mathbf{4}$ & $\mathbf{3}$ \\
\hline
\end{tabular}

Наряду с фармацевтической промышленностью на фоне пандемии новой коронавирусной инфекции в мире и России организации только еще одной подотрасли из 24, входящих в обрабатывающих производства, - производство табачных изделий - демонстрируют уверенность. Однако руководителей, пессимистически ожидающих снижения выпуска продукции, подавляющее большинство.

Высокие темпы развития отечественной фармацевтической отрасли за последние 10 лет, рост инвестиционной активности, постепенный переход на инновационную модель развития и решения проблем импортозамещения зависят от многих социально-экономических факторов, в том числе и от государственной поддержки отрасли с 2013 г., когда была принята федеральная целевая программа «ФАРМА-2020».

За эти годы было запущено множество фармацевтических производств, которые позволят реализовать программу импортозамещения лекарственных препаратов, а также производить инновационные лекарственные препараты на территории России. В соответствии с программой заключены сотни контрактов на разработку технологий по производству жизненно необходимых и важнейших лекарственных препаратов, трансферт зарубежных разработок инновационных лекарств, клинических и доклинических исследований лекарств. Однако в настоящее время остается ориентация отрасли на выпуск несложных, в первую очередь жизненно важных, лекарственных средств и препаратов, обеспечивающих первоочередные потребности населения.

В 2020 г. будут подводиться итоги стратегии «ФАРМА-2020», в то время как министерством промышленности и торговли Российской Федерации размещен на общественное обсуждение проект распоряжения Правительства Российской Федерации «Об утверждении Стратегии развития фармацевтической промышленности Российской Федерации на период до 2030 г.».

В стратегии «ФАРМА-2030» сохраняются основные цели действующей программы, но представлены новые стратегические задачи - усиление государственной политики по поддержке инноваций, развитие локальных компетенций в

${ }^{1}$ Социально-экономическое положение России: доклад Федеральной государственной службы России (Росстат). Январь — февраль, январь — март 2020. URL: https://gks.ru/compendium/document/50801 (дата обращения: 10.08.20). 
химическом и биологическом синтезе активных веществ и фармацевтических субстанций. Для фармацевтический отрасли России нужны новые приоритеты и стимулы для развития.

\section{Литература}

1. Баталова А. Погоня за лидерами // Российская газета. Специальный проект Rg.ru Digital. 2020. URL: https://rg.ru/2020/02/11/samoj-innovacionno-aktivnoj-otrasliu-ekonomikistala-promyshlennost.html (дата обращения: 10.08.20).

2. Артемов С. Состояние отечественного производства фармацевтических субстанций [Электронный pecypc]. URL: http://newchemistry.ru/ letter.php?n_id=7002 (дата обращения: 10.08.20).

\section{PHARMACEUTICAL INDUSTRY IN RUSSIA: ANALYSIS AND ECONOMIC ASPECTS OF DEVELOPMENT}

Svetlana E. Radnaeva

Cand. Sci. (Econ.)

E-mail: radnasv@gmail.com

Irina V. Matskevich

Cand. Sci. (Sociol.), A/Prof.

E-mail: mazkevich@yandex.ru

Elena M. Ukhakshinova

Assistant,

E-mail: ukh.elema@mail.ru

Dorzhi Banzarov Buryat State University

24a Smolina St., Ulan-Ude 670000, Russia

Over the past 10 years the pharmaceutical industry in Russia has been a dynamically growing non-resource sector of the economy and demonstrated active sustainable growth every year, surpassing the growth of the rest of the economy as a whole. The article analyzes the development of the industry in terms of the main economic indicators over the past 7-10 years in comparison with the most important indicators of the national economy; the main gross indicators and indices of organizations by type of economic activity: production of pharmaceutical products, pharmaceutical substances, medicinal drugs and materials used for medical purposes. We have revealed the main trends of fixed investments in the pharmaceutical industry, determined the structure of the volume of shipped own-produced goods, executed services by forms of ownership, and shown business confidence indexes of manufacturing and pharmaceutical organizations. The article presents the results of state policy set in Federal Target Program "PHARMA-2020", which is aimed at the development of pharmaceutical industry, as well as new priorities of the draft strategy "PHARMA-2030".

Keywords: pharmaceutical sector; pharmaceutical industry; "PHARMA-2020" strategy; "PHARMA-2030" strategy. 